\title{
A Mating Aggregation of the Spider Crab (Libinia emarginata)
}

\author{
Robert E. DeGoursey \\ Marine Sciences Institute \\ The University of Connecticut at Avery Point \\ Groton, Connecticut 06340, USA \\ and \\ Peter J. Auster \\ NOAA's National Undersea Research Center \\ The University of Connecticut at Avery Point \\ Groton, Connecticut 06340, USA
}

\begin{abstract}
Observations made while SCUBA diving report for the first time in the spider crab (Libinia emarginata) the occurrence of a mating aggregation in Fishers Island Sound, Connecticut, USA. Observations between 30 April and 20 May 1986 showed the aggregation covered a depth range of $5-8 \mathrm{~m}$ and an area of approximately $5000 \mathrm{~m}^{2}$ at a density of approximately $1 \mathrm{crab} / \mathrm{m}^{2}$. There was no significant difference between the sizes of mature females and ovigerous females. Paired males were significantly larger than unpaired males in the overall population, while paired females were not significantly larger than unpaired females in the overall population. There was no correlation between male and female size in paired crabs. Observations of agonistic bouts between males, and male-female pairs exhibiting "obstetrical" behavior, supplement previously published laboratory observations. However, the observations of "obstetrical" behavior showed it had a wider context that involved mature, nonovigerous females as well as females with newly-extruded eggs, and suggested that this behavior should instead be called "protective" behavior.
\end{abstract}

\section{Introduction}

The spider crab, Libinia emarginata (Family Majidae), occurs from Nova Scotia to the western Gulf of Mexico and occupies any type of bottom from the shoreline to $49 \mathrm{~m}$ and occasionally to 124 m (Williams, 1984). Majid crabs such as $L$. emarginata exhibit both primiparous and multiparous mating (Hartnoll, 1969). Hinsch (1969) found that males can mature at a carapace length as short as $19 \mathrm{~mm}$ and that spermatophores are produced throughout the year. Multiparous mating has been observed in the laboratory (Hinsch, 1968, 1972; Hinsch and Walker, 1974).

Some brachyuran crab populations aggregate during mating or molting. Aggregations have been reported for Maja squinado (Carlisle, 1957), Paralithodes camtschatica (Powell and Nickerson, 1965; Dew, 1990), and Chionoecetes opilio (Hooper, 1986). DeGoursey and Stewart (1985) described molting L. emarginata forming large "pods" in October. No mating was observed and crabs dispersed after molting. During winter, crabs once again aggregated in deeper water in dense patches where they remained burrowed into the substrate until spring (DeGoursey and Auster, unpublished observations). Herein we report on a mating aggregation observed in May. These represent the first in situ observations of mating activities and associated behaviors in L. emarginata.

\section{Study Site and Methods}

The subtidal study site was located off the east point of Ram Island, Connecticut $41^{\circ} 18^{\prime} 41^{\prime \prime} \mathrm{N}$, $72^{\circ} 58^{\prime} 34^{\prime \prime} \mathrm{W}$ (Fig. 1). Depth ranged from 5 to $8 \mathrm{~m}$ sloping from the northwest to the southeast. The substrate was primarily sandy-mud with well sorted shell debris. Boulder fields extended from the east point of the island to a depth of $6 \mathrm{~m}$ and the largest dimensions of the boulders ranged from 0.5-2.0 m. Horizontal surfaces of the boulders were covered with macroalgae including species of Laminaria, Chondrus, and Ceramium. The boulder habitat provided shelter for numerous resident organisms including lobster (Homarus americanus) and Jonah crab (Cancer borealis).

Observations and samples were obtained while SCUBA diving on 30 April, 1, 5, 8, 14 and 20 May 1986. Additional observations were made on 16, 19 and 25 May 1989. Observations were recorded immediately following each dive. Photographs and video footage were taken to record behavioral observations. Areal coverage of the aggregation and density of individuals were estimated visually. 


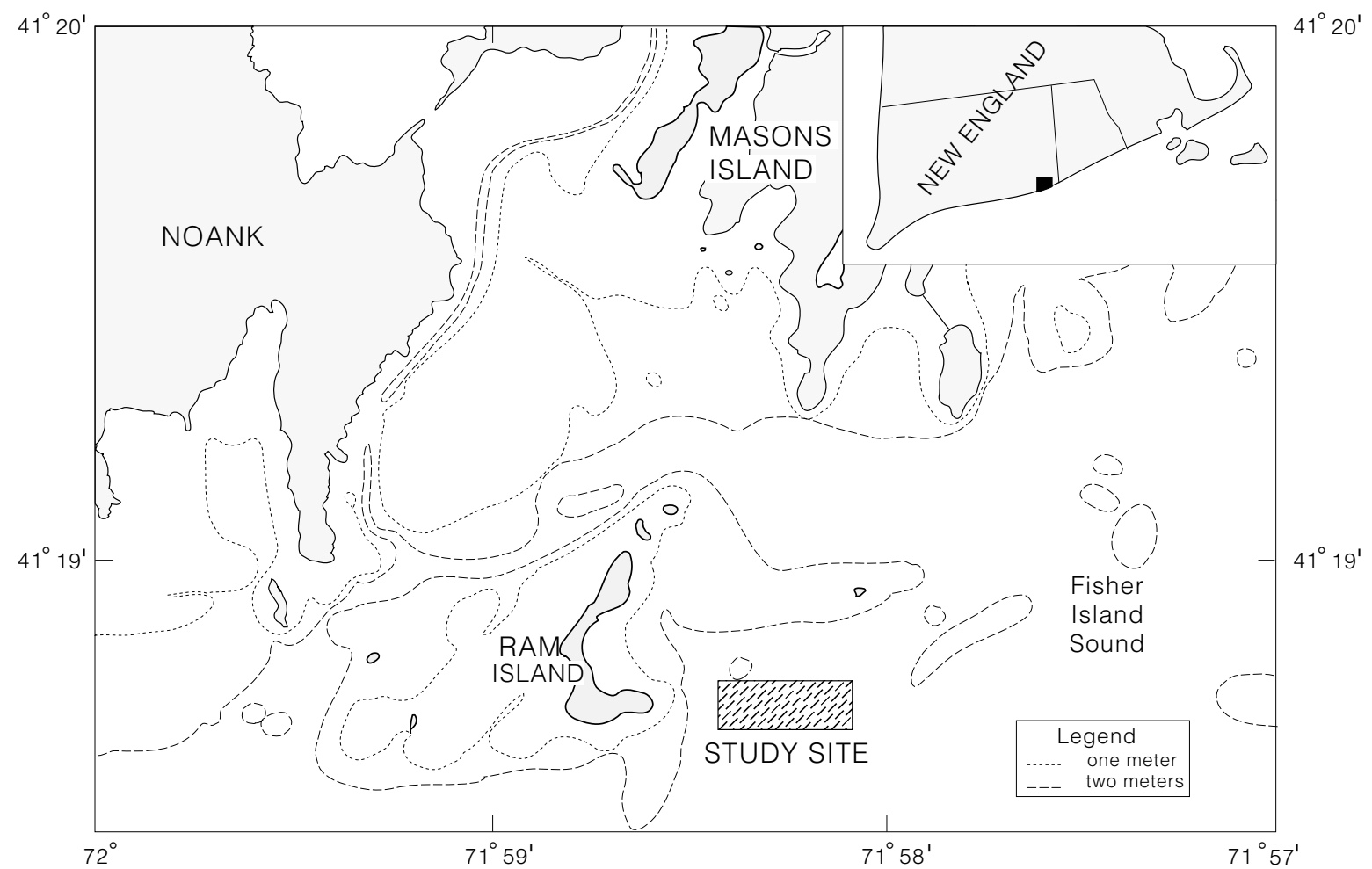

Fig. 1. The study site near Ram Island, Connecticut where mating aggregations of Libinia emarginata were observed in 1986 and 1989.

Representative samples of crabs were collected during dives on 1, 5 and 8 May, 1986 while only the number of ovigerous females was determined during dives on 14 and 20 May 1986. Paired crabs were collected during all dives in 1986 and kept separate from the others. All collected crabs were sexed and carapace length (CL), from the notch of the rostrum to the posterior margin of the carapace, was measured to the nearest $0.1 \mathrm{~mm}$. The abdominal flap of female crabs and egg clutches were examined to differentiate between immature and mature individuals (Hinsch, 1972). Shell condition was also noted (e.g. intermolt, postmolt). Collected crabs were not returned to the study site.

\section{Results}

\section{Spatial relationships}

A mating aggregation was first observed on 30 April 1986 in an area where few crabs were seen in March. It covered an area approximately $5000 \mathrm{~m}^{2}$ at a density of approximately $1 \mathrm{crab} / \mathrm{m}^{2}$. Another mating aggregation was observed in exactly the same location at around the same density in May 1989. In 1986 crabs had begun to disperse from the study area within 15 days of the original sighting based on reduced densities ( $<1 \mathrm{crab} / 10 \mathrm{~m}^{2}$ ) ob- served during the dives on 14 and 20 May. The water temperature ranged from $9.5^{\circ}$ to $13.0^{\circ} \mathrm{C}$ during all observations.

\section{Population parameters}

The sex ratio of the 1986 mating aggregation was 1.1:1 (M:F). The mean size of mature, nonovigerous females was $60.6 \mathrm{~mm} \mathrm{CL}$ which was similar to the $60.2 \mathrm{~mm}$ mean $\mathrm{CL}$ of ovigerous females (Table 1; t-test, $P>0.10$ ). Although the size range of immature females overlapped that of the matures by $8.5 \mathrm{~mm}$, their mean size (46.2 $\mathrm{mm} \mathrm{CL}$ ) was substantially smaller (t-test, $P<0.05$ ).

Seventeen pairs of crabs were collected and sizes compared to the unpaired crab population. Paired females were not significantly different from unpaired females (60.3 mm mean CL for both groups; $P>0.10$ ) while paired males were significantly larger than unpaired males $(87.7 \mathrm{~mm}$ mean $\mathrm{CL}$ versus 71.8 $\mathrm{mm} ; \mathrm{P}<0.01)$. There was no correlation between the size of paired male and female crabs $\left(r^{2}=0.00\right)$.

In the 1986 samples, the percentage of mature females that were ovigerous increased from $26 \%$ ( $n$ $=19$ ) on 1 May to $39 \%(n=98)$ on 5 May to $98 \%$ ( $n$ $=67)$ on 8 May and finally to $100 \%$ on $14(n=40)$ and 
TABLE 1. Size composition of male and female Libinia emarginata from a mating aggregation near Ram Island, Connecticut in 1986.

\begin{tabular}{lccccc}
\hline \hline & All males & All females & $\begin{array}{c}\text { Mature } \\
\text { Nonovigerous } \\
\text { females }\end{array}$ & $\begin{array}{c}\text { Ovigerous } \\
\text { females }\end{array}$ & $\begin{array}{c}\text { Immature } \\
\text { females }\end{array}$ \\
\hline N & 234 & 211 & 73 & 11 & 27 \\
MEAN & 71.8 & 58.5 & 60.6 & 60.2 & 46.2 \\
S.D. & 16.4 & 7.1 & 5.8 & 4.6 & 6.3 \\
MIN. & 32.8 & 31.8 & 48.7 & 48.6 & 31.8 \\
MAX. & 103.8 & 72.7 & 72.7 & 72.1 & 57.1 \\
\hline
\end{tabular}

$20(n=35)$ May. Only one specimen from 8 May 1986 had a well-developed, eyed egg mass; all others were bright orange indicating these were newly extruded. All crabs ( $n=445$ in 1986) collected during the study were in intermolt condition.

\section{Behavioral observations}

Copulating crabs ( $\mathrm{n}=8$ pairs) were observed on 30 April and 5 May 1986 and again on 16 May 1989 (Fig. 2). The male firmly grasped the female rostrum with his chelae and using his walking legs positioned her abdomen against his in a copulatory posture. During copulation the abdominal flaps of both crabs were extended. Mating occurred with both crabs standing on their walking legs or with the male lying on his carapace with the female on top of him. One pair (83.5 mm CL male and $60.4 \mathrm{~mm}$ CL female) observed on 16 May 1989 maintained a copulatory embrace for approximately 15 minutes until disturbed by a second male (76.7 $\mathrm{mm} \mathrm{CL}$ ).

Paired crabs were observed in a variety of postures. The most common was the so-called "obstetrical" posture (Hinsch, 1968) in which the female was manipulated by the male's walking legs and chelae so that her carapace was behind his with the posterior margin of their carapaces touching (Fig. 3). The fourth pair of walking legs of the male was clasped around the female's carapace dorsally. The tips of the male's dactyls were inserted between the females walking legs. The female was maintained in this position whether the male was stationary or walking. In most cases the larger male carried the female such that her walking legs did not come in contact with the bottom. The obstetrical posture also leaves the male's chelae unobstructed for feeding and defense. The obstetrically paired

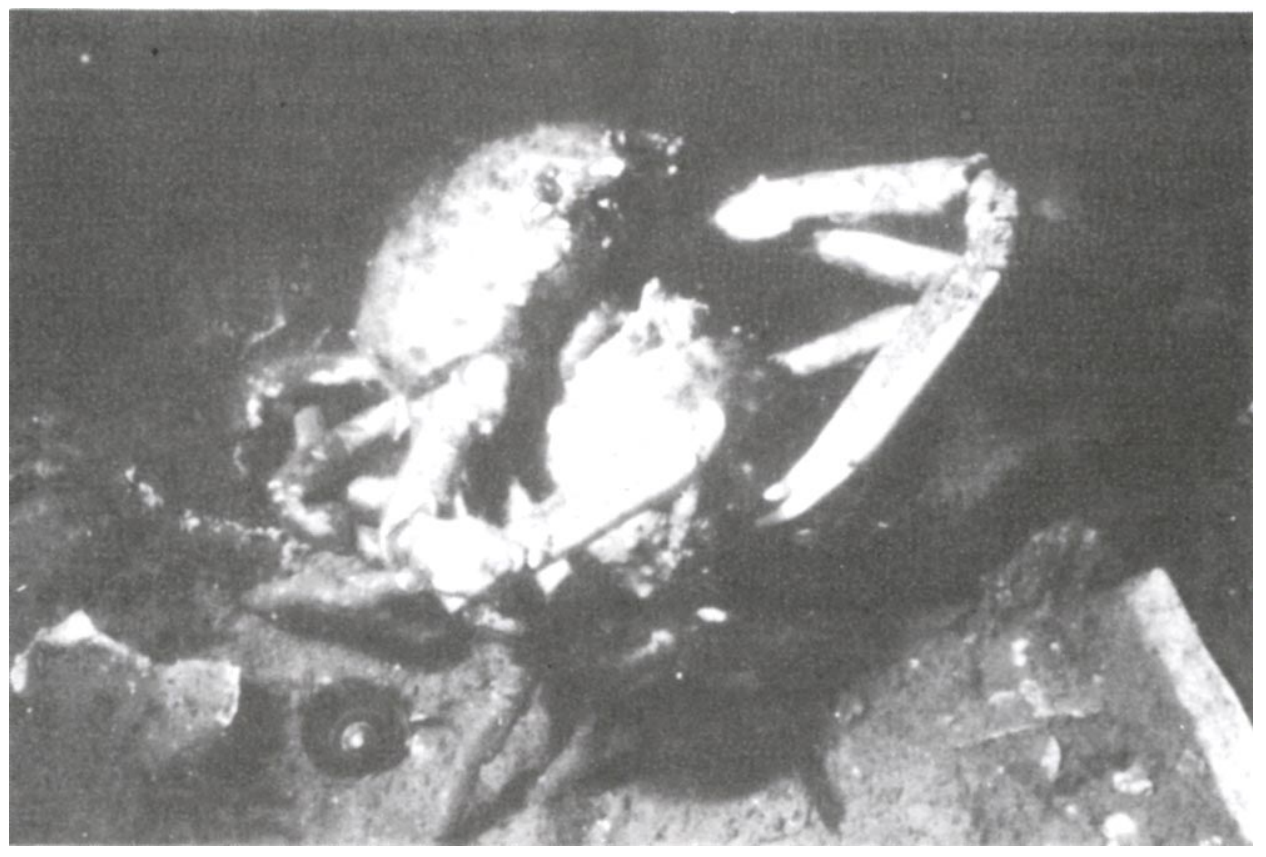

Fig. 2. A pair of Libinia emarginata in the copulatory embrace. Note the conspicuously large chelae of the male (left). 


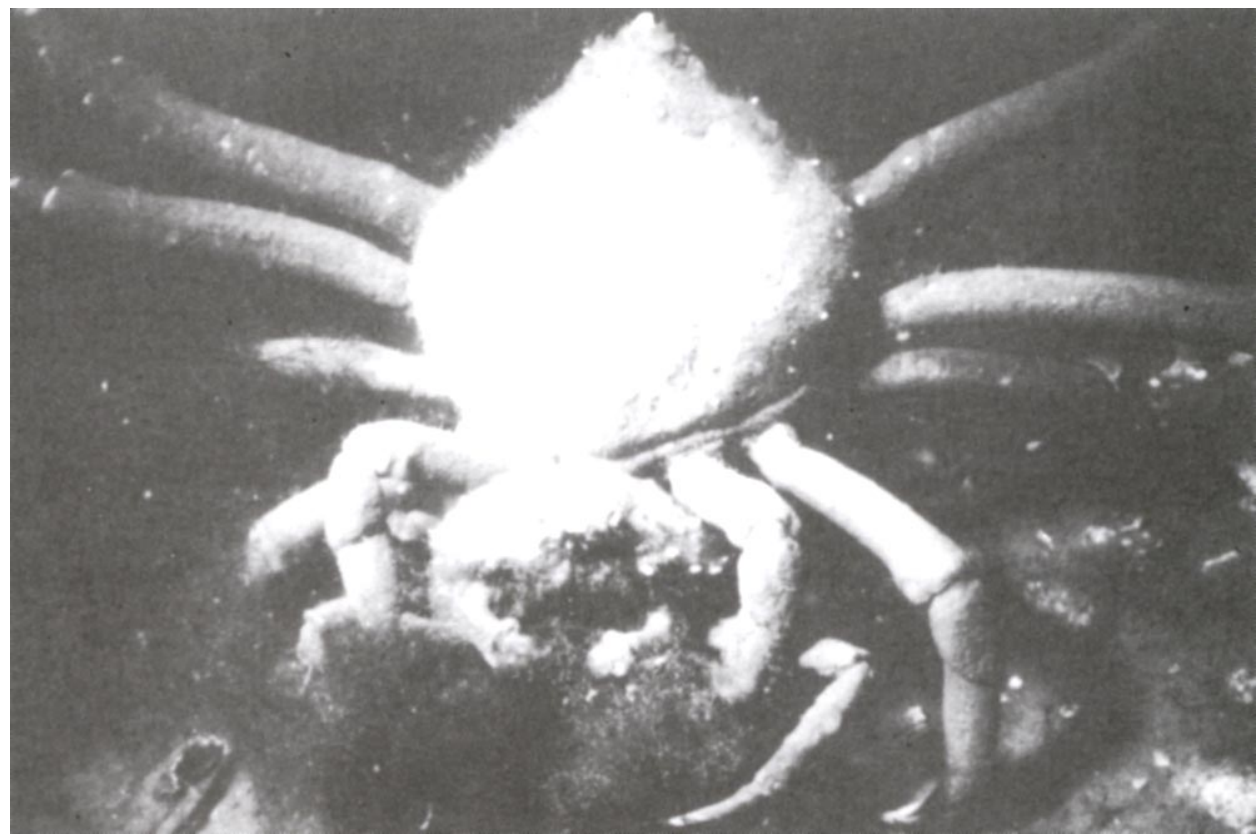

Fig. 3. A large male Libinia emarginata and a smaller female exhibiting obstetrical behavior. The tips of the dactyls effectively immobilize the female.

female crabs collected were either mature, nonovigerous ( $n=12$ ) or ovigerous with newlyextruded, bright orange eggs $(n=5)$.

Other postures during pairing involved less contact. Females were often found upright and partially buried with a male upright above her. The male, with his abdominal segments, would maintain contact with the female's carapace. When confronted by another male, the paired male would rise up on the tips of his dactyls, "caging" the female, and extend his chelae. All females in these pairs were mature. The context in which this behavior occurs (i.e. pre- or post-mating) was not determined.

Agonistic bouts $(n=12)$ between males were observed on nearly every dive (Fig. 4). Females were often present. Bouts were generally of short duration, lasting less than 30 seconds but occasionally up to 60 seconds. Crabs confronted one another with chelae raised to push or grasp an opponent but no injuries were inflicted. Presumably, these bouts took place for possession of a female. On one occasion, 5 May 1986, a male (59.0 $\mathrm{mm} \mathrm{CL)}$ was copulating with a female when a larger male (89.0 $\mathrm{mm} \mathrm{CL}$ ) approached and challenged. The larger male maneuvered the pair against a boulder and pinned the smaller male's chelae with his own. The female was retained between the fighting males until the larger male used his walking legs to pull the female away and reposition her beneath his carapace. The large male then released his opponent and walked away with the female caged beneath. A similar interaction was observed on 16 May 1989 when a copulating pair was challenged by a smaller male. In this instance, the larger male was able to retain possession of the female.

Paired crabs were always in contact with the sandy-mud bottom but individuals ascended to the tops of boulders to forage on algae. Individual crabs, especially females, also partially burrowed into the bottom. Many of these females were ovigerous.

Little evidence of predation on crabs was observed. The remains of eight $L$. emarginata were found with the carapace split and legs either missing or scattered near the carapace. H. americanus prey on large decapod crustaceans and leave remnants in this way (Weiss, MS 1970; DeGoursey and Auster, unpublished observations).

\section{Discussion}

These are the first reported field observations of a mating aggregation of $L$. emarginata. The formation of molting "pods" of $L$. emarginata was alluded to by Aldrich (1974). DeGoursey and Stewart (1985) provided detailed observations on a molting aggregation located in 1973 within $40 \mathrm{~m}$ of the mating aggregation reported in this paper. It would seem that this general area has some preferential feature(s). The factors involved in site selection by the crabs can only be speculated on at this time. Depth, sediment type, topography and faunal/floral 


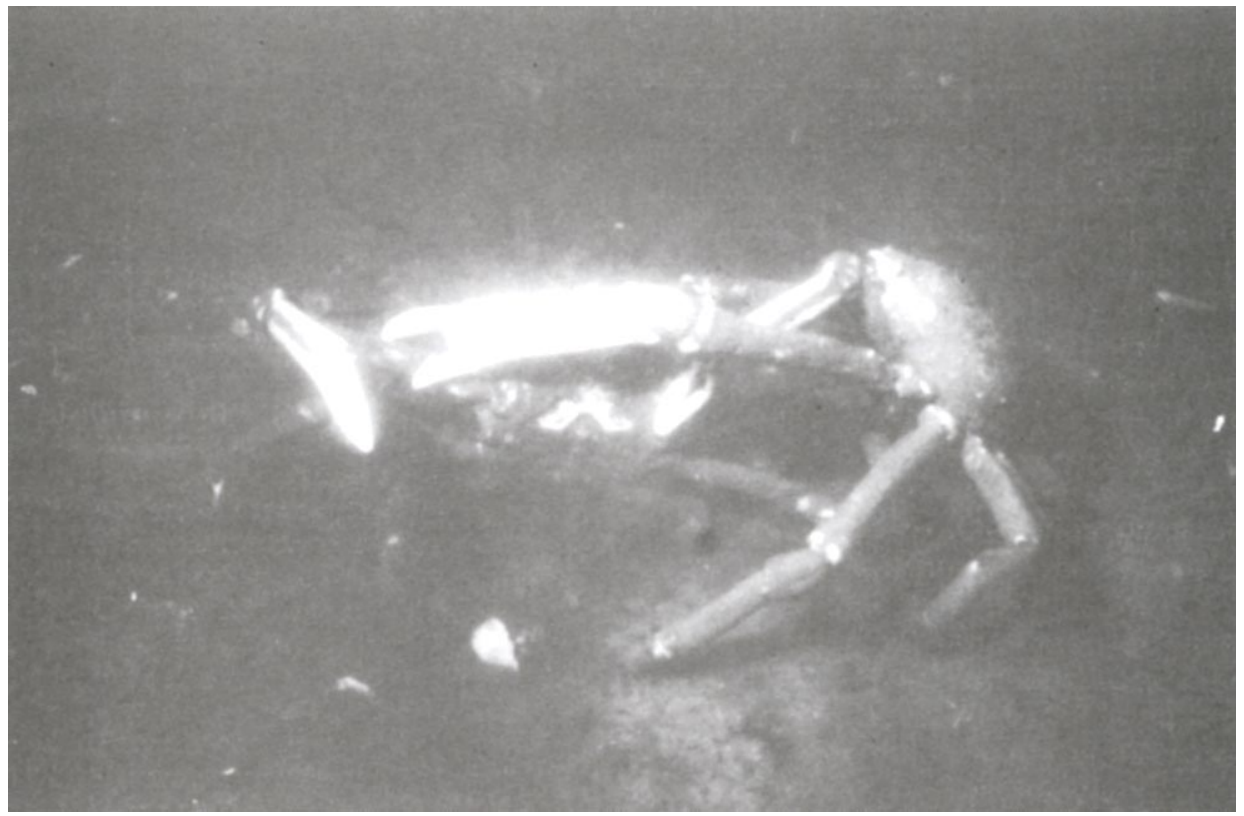

Fig. 4. An agonistic encounter between two male Libinia emarginata. These fighting bouts are ritualistic and do not result in injury.

assemblages appear to be similar at each site. Hinsch (1968) speculated about the production of pheromones by L. emarginata but this has not been confirmed. Aggregations could initially focus around several crabs and subsequently build in size.

Few actual copulations were observed, while the percentage of ovigerous females increased from 26 to 100 during our observations. Nearly $100 \%$ of the egg masses we examined were newly extruded. This would suggest that intense mating activity had taken place either just prior to our observations or at other times of the day such as in the night.

Hinsch (1968) reported that female L. emarginata are capable of producing 3-4 successive broods during the mating season with egg development to hatching requiring approximately 25 days at Woods Hole, Massachusetts, USA. We collected only one female with eggs in an advanced state of development. It appears that following mating, the females extrude eggs and disperse to brood the egg mass and eventually release the zoeae. Subsequent broods may be produced from the same mating since the females can retain spermatophores in their seminal receptacles (Hinsch, 1968).

Our observations of "obstetrical" behavior in L. emarginata depart from laboratory observations reported by Hinsch (1968), who found obstetrical behavior involving only ovigerous females bearing eggs about to hatch. We only observed obstetrical behavior involving mature, nonovigerous females or females with newly-extruded eggs. Clearly, this behavior is not limited to protecting the female during zoeal release as suggested by Hinsch (1968). Although we do not have observations of single pairs of crabs throughout the mating process, our observations are consistent with the supposition that obstetrical behavior occurs prior to mating and subsequent egg extrusion.

Obstetrical behavior has only been reported in one other oxyrhynchan species, Loxorhynchus grandis (Hanauer, 1988). The anecdotal observations of $L$. grandis suggest this positioning is a precopulatory posture. Due to the varying context in which this behavior is used both in L. emarginata and L. grandis, we suggest changing the name from "obstetrical" behavior to "protective" behavior. This terminology reflects the wider context in which this behavior occurs.

Why does this type of protective behavior occur in so few species? Most brachyuran males hold the female beneath the carapace. A male L. emarginata may not be able to walk with a female held beneath his carapace, especially in a current, because the female of this species is much deeper bodied compared to other brachyurans. For the male, carrying the female with the rear walking legs may result from anatomical necessity. Another reason for the rarity of this behavior may be that other brachyurans have demonstrated affinities for shelters (e.g. Fogarty, MS 1976) and those species could not utilize the $L$. emarginata protective posture because the pair 
would not fit into confined spaces such as rock crevices.

The gregarious behavior demonstrated by $L$. emarginata during molting (DeGoursey and Stewart, 1985), overwintering (DeGoursey and Auster, unpublished observations) and mating (this study) may reduce predation during life history phases when the crabs are most vulnerable. Very low predation rates were discerned during our observations.

The type of aggregation which we describe for L. emarginata is most similar to that described by Hooper (1986) for C. opilio. Both species occurred in aggregations at approximately the same densities. However, all L. emarginata mating was multiparous while $C$. opilio mating included primiparous females as well. No "pods" were reported during mating activities for either of these species. Carlisle (1957) described primiparous mating and molting aggregations of $M$. squinado. Seasonally, crabs formed large "heaps" with mature males and immature males and females. As females molted in the center of the aggregation, they immediately mated with one of the mature males. No aggregations of any kind have been observed during multiparous mating of M. squinado (Hartnoll, 1969). The complexity of social interactions in mating aggregations of Majid crabs are apparently quite variable and probably depend primarily on molt state. Field observations of primiparous mating of $L$. emarginata have not been made, but presumably occurs as in C. opilio.

\section{Acknowledgements}

This study was supported by the Marine Sciences Institute and NOAA's National Undersea Research Center at the University of Connecticut. The authors sincerely appreciate the efforts of Michelle MarcAurele who patiently typed several drafts, and the editorial comments of Douglas Lee and two anonymous reviewers.

\section{References}

ALDRICH, J. C. 1974. Allometric studies on energy relationships in the spider crab Libinia emarginata (Leach). Biol. Bull., 147: 257-273.

CARLISLE, D. B. 1957. On the hormonal inhibition of moulting in decapod crustacea. II. The terminal anecdysis in crabs. J. Mar. Biol. Assoc. U.K., 36: 291-307.

DeGOURSEY, R. E., and L. L. STEWART. 1985. Spider crab podding behavior and mass molting. Underwat. Nat., 15: 12-16.

DEW, C. B. 1990. Behavioral ecology of podding red king crab, Paralithodes camtschatica. Can. J. Fish. Aquat. Sci., 47: 1944-1958.

FOGARTY, M. J. MS 1976. Competition and resource partitioning in two species of Cancer (Crustacea, Brachyura). M. S. Thesis, University of Rhode Island, Kingston, $96 \mathrm{p}$.

HANAUER, E. 1988. Spider crab orgy. Skin Diver., 37(6): $28 \mathrm{p}$.

HARTNOLL, R. G. 1969. Mating in the Brachyura. Crustaceana, 16: 161-181.

HINSCH, G. W. 1968. Reproductive behavior in the spider crab Libinia emarginata (L.). Biol. Bull., 135: 273-278.

1969. Microtubules in the sperm of the spider crab, Libina emarginata L. J. Ultrastruc. Res., 29: $525-534$.

1972. Some factors controlling reproduction in the spider crab, Libinia emarginata. Biol. Bull., 143: 358-366.

HINSCH, G. W., and M. H. WALKER. 1974. The vas deferens of the spider crab, Libinia emarginata. J. Morphol., 143: 1-19.

HOOPER, R. G. 1986. A spring breeding migration of the snow crab Chionoecetes opilio (O. Fabr.), into shallow water in Newfoundland. Crustaceana, 50: 257264.

POWELL, G. C., and R. B. NICKERSON. 1965. Aggregations among juvenile king crabs (Paralithodes camtschatica, Tilesius), Kodiak, Alaska. Anim. Beh., 13: 374-380.

WEISS, H. M. MS 1970. The diet and feeding behavior of the lobster, Homarus americanus, in Long Island Sound. Ph. D. Dissertation, The University of Connecticut, Storrs., 80 p.

WILLIAMS, A. B. 1984. Shrimps, lobsters, and crabs of the Atlantic coast of the eastern United States, Maine to Florida. Smithsonian Institution Press, Washington, D. C. 